This item was submitted to Loughborough's Research Repository by the author.

Items in Figshare are protected by copyright, with all rights reserved, unless otherwise indicated.

\title{
Accounting for sitting and moving: an analysis of sedentary behaviour in mass media campaigns
}

\section{PLEASE CITE THE PUBLISHED VERSION}

http://dx.doi.org/10.1123/jpah.2014-0360

\section{PUBLISHER}

(c) Human Kinetics, Inc.

\section{VERSION}

AM (Accepted Manuscript)

\section{PUBLISHER STATEMENT}

This work is made available according to the conditions of the Creative Commons Attribution-NonCommercialNoDerivatives 4.0 International (CC BY-NC-ND 4.0) licence. Full details of this licence are available at: https://creativecommons.org/licenses/by-nc-nd/4.0/

\section{LICENCE}

CC BY-NC-ND 4.0

\section{REPOSITORY RECORD}

Knox, Emily C., Stuart J.H. Biddle, Dale W. Esliger, Joe Piggin, and Lauren B. Sherar. 2019. "Accounting for Sitting and Moving: An Analysis of Sedentary Behaviour in Mass Media Campaigns”. figshare. https://hdl.handle.net/2134/18810. 


\section{Note: This article will be published in a forthcoming issue of the Journal of Physical Activity \& Health. This article appears here in its accepted, peer-reviewed form, as it was provided by the submitting author. It has not been copy edited, proofed, or formatted by the publisher.}

Section: Original Research

Article Title: Accounting for Sitting and Moving: An Analysis of Sedentary Behaviour in Mass Media Campaigns

Authors: Emily Knox, Stuart Biddle, Dale W. Esliger, Joe Piggin, and Lauren Sherar

Affiliations: The authors are with the Department of Sport, Exercise and Health Sciences, Loughborough University, Loughborough, Leicestershire, UK.

Running Head: Analysis of sedentary behaviour in media campaigns

Journal: Journal of Physical Activity \& Health

Acceptance Date: October 17, 2014

(C)2014 Human Kinetics, Inc.

DOI: http://dx.doi.org/10.1123/jpah.2014-0360 
“Accounting for Sitting and Moving: An Analysis of Sedentary Behaviour in Mass Media Campaigns” by Knox E et al. Journal of Physical Activity \& Health

(C) 2014 Human Kinetics, Inc.

Accounting for sitting and moving: An analysis of sedentary behaviour in mass media campaigns

Original Article

Abstract word count: 196

Manuscript word count: 5,562 
“Accounting for Sitting and Moving: An Analysis of Sedentary Behaviour in Mass Media Campaigns” by Knox E et al. Journal of Physical Activity \& Health

(C) 2014 Human Kinetics, Inc.

\section{Abstract}

Background: Mass media campaigns are an important tool for promoting health-related physical activity. The relevance of sedentary behaviour to public health has propelled it to feature prominently in health campaigns across the world. This study explored the use of messages regarding sedentary behaviour in health campaigns within the context of current debates surrounding the association between sedentary behaviour and health, and messaging strategies to promote moderate-to-vigorous physical activity (MVPA). Methods: A webbased search of major campaigns in the UK, US, Canada and Australia was performed to identify the main campaign from each country. A directed content analysis was then conducted to analyse the inclusion of messages regarding sedentary behaviour in health campaigns and to elucidate key themes. Important areas for future research were illustrated. Results: Four key themes from the campaigns emerged: clinging to sedentary behaviour guidelines, advocating reducing sedentary behaviour as a first step on the activity continuum and the importance of light activity, confusing the promotion of MVPA and the demonization of sedentary behaviour. Conclusions: Strategies for managing sedentary behaviour as an additional complicating factor in health promotion are urgently required. Lessons learned from previous health communication campaigns should stimulate research to inform future messaging strategies.

Keywords: Health promotion, messages, physical activity 
“Accounting for Sitting and Moving: An Analysis of Sedentary Behaviour in Mass Media Campaigns” by Knox E et al. Journal of Physical Activity \& Health

(C) 2014 Human Kinetics, Inc.

\section{Introduction}

Sedentary behaviour poses a health risk to adults which appears to be largely independent of the effects of moderate-to-vigorous physical activity (MVPA) ${ }^{1,2}$, although findings for children are less clear ${ }^{3}$. Debate around what constitutes sedentary behaviour ${ }^{4,5}$ led the Sedentary Behaviour Research Network (SBRN) to define it as "any waking behaviour characterized by an energy expenditure $\leq 1.5$ METs while in a sitting or reclining posture" physical activity guidelines (or an equivalent agreed criterion). It is therefore possible for an individual to be both active and sedentary over time, although evidence suggests that those who are active are somewhat less likely to be sedentary ${ }^{7}$. With many individuals failing to meet physical activity guidelines for $\mathrm{MVPA}^{8}$ the problem of inactivity and the problem of a sedentary lifestyle inflict a potential 'double blow' to health ${ }^{7}$.

The proportion of the day spent being sedentary is increasing for many people $\mathrm{e}^{9,2}$. Many urban environments contribute to this trend. For instance, city workplaces are officebased and school children sit at desks for most of the day. UK adults are spending increasingly more time on computers and less time actively commuting (teleworking increased by $46 \%$ between 2006 and $2011^{10,11}$ ). Similar trends are seen in children. For example, between 2011 and 2012, children aged 12-15 spent an additional 2.2 hours per week on the computer and the number owning smartphones/tablets increased by more than eight percent $^{12}$. Active commuting amongst children has also decreased by $12 \%$ since $2005^{13}$. The threat of an increasingly sedentary and inactive lifestyle is a global problem ${ }^{14,15}$. Mass media campaigns have been identified as a potentially useful strategy for promoting improved health behaviours ${ }^{16}$.

The proven inverse relationship between sedentary behaviour and health has generated growing media interest in recent years as the following newspaper headlines 
“Accounting for Sitting and Moving: An Analysis of Sedentary Behaviour in Mass Media Campaigns” by Knox E et al. Journal of Physical Activity \& Health

(C) 2014 Human Kinetics, Inc.

demonstrate: "Sitting for long periods is 'bad for your health"”17; "Exercise: How to keep fit at your desk"18. Evidence of distinct health benefits with reducing or breaking up sedentary time has provided health promoters with a cluster of new health behaviours to target ${ }^{19}$. Indeed, health promoters have begun to pick up on the sedentary message with an increasing number of initiatives targeting specific sedentary behaviours ${ }^{20,21,22}$. Examples include, activity report cards to monitor children's sitting behaviour ${ }^{23}$ and standing meetings advised in books such as "Up the Organization" 24 . It follows that reducing sedentary time should be another goal of health promotion campaigns and that existing mass media campaigns, which already promote physical activity and so benefit from having an existing infrastructure and brand profile, will take the lead. The aim of this paper was to conduct a detailed analysis of the content in current mass media campaigns to inform understanding around the use of messages regarding sedentary behaviour in health campaigns. This content was considered within the context of current debates surrounding the association between sedentary behaviour and health, and messaging strategies to promote MVPA.

\section{Methods}

This study employed a directed content analyses ${ }^{25}$. First, an internet search of literature from the UK, US, Canada and Australia of existing mass media campaigns associated with physical activity and sedentary behaviour was conducted between January and February 2014. These four countries were selected because they were all identified to have released important government sponsored physical activity/and or sedentary behaviour documents since the global physical activity guidelines (with reference to sedentary behaviour) were disseminated and were therefore deemed likely to have conducted concerted promotional efforts in recent years ${ }^{8,26,27,28}$. Non-English speaking countries were not included. 
“Accounting for Sitting and Moving: An Analysis of Sedentary Behaviour in Mass Media Campaigns” by Knox E et al. Journal of Physical Activity \& Health

(C) 2014 Human Kinetics, Inc.

The search terms used were; "physical activity campaign/promotion/messages", "sedentary behaviour campaign/promotion/messages", "health campaign/promotion/ messages" and their related words. It was an objective of this paper to explore the most highly visible mass media campaigns, thus we opted to explore those most likely to have public health influence from each selected country. Campaigns were selected based on the amount of media communications related to them which suggested they had received more publicity than other campaigns in their host nations and so were the most influential. Materials from the following campaigns were therefore analysed: United Kingdom (Change4Life), Canada (ParticipACTION), USA (5210) and Australia (Heart Foundation campaigns; Be Active, Measure Up, Swap it Don't Stop It and Shape Up). Table 1 provides a list of the campaigns and examples of the messages they have released.

5210 is a campaign that targets the behaviour of children, the Heart Foundation campaigns target adults, while Change4Life and ParticipACTION target both adults and children, thus the selected campaigns provided important perspectives for promotion to both adults and children. All media related to the campaign was considered including websites, television advertisements, newsletters and posters. Campaign messages were read and critically re-read in order to develop themes about the promotional techniques which are being utilised by physical activity promoters. The framing of sedentary behaviour in relation to other health behaviours was considered.

After a period of familiarisation with the materials of the selected campaigns, campaign messages with the aim of reducing sedentary behaviour were identified and communications were categorised thematically. Messages were tabulated alongside their respective campaigns and from this themes were identified. Messages were read and re-read with key words or phrases highlighted in order to develop themes. An independent researcher later examined the tabulated messages in order to establish agreement regarding the selected 
“Accounting for Sitting and Moving: An Analysis of Sedentary Behaviour in Mass Media Campaigns” by Knox E et al. Journal of Physical Activity \& Health

(C) 2014 Human Kinetics, Inc.

themes. Some of the challenges faced by health promoters producing messages targeting the reduction of sedentary behaviour, and the partnering of messages on sedentary behaviour and messages on physical activity within comprehensive over-arching campaigns are discussed throughout. Therefore, rather than analysing the various campaigns individually, the campaigns were compiled and analysed collectively in order to develop key themes.

\section{Results}

\section{Theme one: Clinging to guidelines}

The content analysis identified a tendency for messages to rely on the sedentary behaviour guidelines to provide content on how much sedentary behaviour individuals should engage in. Health campaigns have adopted messages with directives which follow the exact wording of guidelines e.g. "engage in no more than two hours of recreational screen time" (5210 Lets Go! Maine $)^{29}$, "setting a limit of two hours max of screen time each day helps make sure kids are active" (Change4Life ${ }^{30}$, and "limit that [screen time] to two hours a day" (ParticipACTION). Through its sub-campaign $U p \& A b o u t^{31}$, Change4Life expressly targets sedentary behaviour of children after school, the area of the day highlighted by guidelines, using messages such as "get up after eating" and "two hours [screen time] max".

\section{Theme two: Reducing sedentary behaviour as a gateway to more active lifestyles}

The content analysis identified a predilection of campaigns towards combining sedentary behaviour messages with messages on physical activity. While MVPA is optimal for health, health benefits can also be obtained through light intensity activity ${ }^{32}$ and even at the low intensity range of standing ${ }^{33}$. However, messages do not tend to focus on simply breaking up sedentary behaviour with light activity. The language and images used often suggest substituting sedentary behaviour with moderate-to-vigorous physical activity. For instance, ParticipACTION messages suggest "Limit that [screen time] to two hours a day and they'll have more time for physical activity!", "Turn off the screens. Turn up the play", and 
“Accounting for Sitting and Moving: An Analysis of Sedentary Behaviour in Mass Media Campaigns” by Knox E et al. Journal of Physical Activity \& Health

(C) 2014 Human Kinetics, Inc.

"unplug and play" (http://www.participaction.com/). The Australian campaign Swap it Don't Stop it urges individuals to "swap sitting for moving" and have released a series of advertisements suggesting a number of swaps for sedentary behaviours e.g. "swap a close park [of your car] for a short walk", "swap your stop and walk part of the way" and "swap a feed for a lead"34. Similarly, 5210 published a series of advertisements all of which emphasised a variety of different forms of physical activity such as, running, jumping, skipping etc. (https://www.facebook.com/5210nwfl). Despite the sedentary message being inherent to the logo and to the campaign aim (http://www.letsgo.org/) moving from sitting to less intense activities such as standing, are not featured in any of the 5210 advertisements.

Light intensity activity is highly correlated with sedentary behaviour suggesting that adults are more likely to replace sedentary behaviour with light activity ${ }^{35}$. In addition, light intensity activity constitutes a greater proportion of behaviour than MVPA. Some messages highlight that reducing sedentary behaviours offers a large proportion of the day to target. For instance, ParticipACTION posters present the messages "The average Canadian kid watches up to eight hours of screens every day. Ninety two percent would rather play. Unplug and go out for some good old fashioned fun" and " $63 \%$ of Canadian kids free time after school and on weekends is spent being sedentary. We need to get our kids moving!" (http://www.participaction.com/get-moving/unplug-play/). All of these messages suggest participation in MVPA, in favour of more attainable substitutions with light activities thereby neglecting a far greater slice of the 'behavioural pie'.

\section{Theme three: Complicating the promotion of MVPA}

As highlighted in theme two, a number of identified campaign messages intimate that replacing sedentary behaviour with other activities will accumulate guideline-fulfilling MVPA. In Change4Life's hallmark television advertisement Alfie; Alfie suggests "[to] swap four wheels for my own two feet to get me going for 150 minutes a week" 
“Accounting for Sitting and Moving: An Analysis of Sedentary Behaviour in Mass Media Campaigns” by Knox E et al. Journal of Physical Activity \& Health

(C) 2014 Human Kinetics, Inc.

(http://www.youtube.com/watch?v=XYKltGcJDRY). The advertisement shows Alfie substituting a common sedentary behaviour (in this case driving) for an active one, thereby becoming less sedentary and more active in the process. Further messages employed in the $U p \&$ About sub-campaign state "setting a limit of two hours max of screen time each day helps make sure kids are active" ${ }^{30}$. Many of the campaigns frequently mention activities such as 'taking the stairs' or 'parking further away' as ways of achieving physical activity guidelines. For instance, LiveLighter, a Be Active campaign states "if you work in an office make your default printer the one furthest away from your desk and force yourself to walk that little bit further to collect your paperwork" (https://livelighter.com.au/).

\section{Theme four: Demonization of sedentary behaviour}

When advertisements of the campaigns portray sedentary behaviour the images are consistently negative. One Change4Life poster reads "Risk an early death just do nothing". The word 'death' is bolded in black so as to stand out whilst the image on the poster is of a bored vacant-looking child sat holding a games controller. Another message in the Change4Life supporter's guide reads "how to limit "vegging out",30 A 5210 television advert shows children kicking

a computer screen (https://www.youtube.com/watch?v=TluNJeM6HAI). The ParticipACTION advertisement "Crisis in Canada" contrasts a number of unenthused individuals on their computers, watching televisions and playing video games, with happy and engaged individuals engaged in physical activity (http://www.youtube.com/watch?v=VNs0gqCn0bg). Negative terms such as "Couch potato" are used. The Australian Swap it, Don't Stop it campaign mascot Eric is a generally cheerful balloon man, except when he is sat in a sofa or car and his smile becomes a frown (http://www.youtube.com/watch?v=AFWM97GelPc). 
“Accounting for Sitting and Moving: An Analysis of Sedentary Behaviour in Mass Media Campaigns” by Knox E et al. Journal of Physical Activity \& Health

(C) 2014 Human Kinetics, Inc.

\section{Discussion}

The content analysis identified four themes of messages promoting reduced sedentary behaviour within mass media campaigns: clinging to guidelines, reducing sedentary behaviour as a gateway to more active lifestyles, complicating the promotion of MVPA and demonization of sedentary behaviour.

Health promotion messages are largely shaped around the guidelines at the time. The first identified theme found this trend in messages regarding sedentary behaviour. Currently, prescriptive guidelines (i.e. guidelines stating a specific volume of sedentary behaviour) around sedentary behaviour exist only for children and so such messages were only identified for the campaigns which produce materials targeting children $(5210$, ParticpACTION and Change4Life). While guidelines regarding sedentary behaviour are available they lack the prescriptive detail found in guidelines for physical activity ${ }^{8}, \operatorname{diet}^{36}$ and alcohol ${ }^{37}$. UK and Australian guidelines for sedentary behaviour currently provide general advice to; "minimise the amount of time spent being sedentary for extended periods (except time spent sleeping)"»8. Canadian guidelines for sedentary behaviour more specifically recommend that recreational screen time be limited to two hours per day ${ }^{38}$. However, dose-response has yet to be identified $^{39}$. It is uncertain whether a longer total sedentary time that is broken up regularly (e.g. an adult or child who sits at a desk all day but gets up for five minutes every hour) is preferable to a shorter total sedentary time that is rarely broken up (e.g. an individual who is only sedentary in the evening but for four hours continuously). Sedentary behaviour guidelines do not prescribe a maximum duration of daily or weekly sedentary time or the specific types of behaviours to limit (e.g. television watching, passive commuting, restraining toddlers in a high chair, etc.) due to the lack of precise evidence to guide such parameters. Previous research by Knox and colleagues suggested that messages which cling closely to physical activity guidelines may be motivationally deleterious when the goal is to increase 
“Accounting for Sitting and Moving: An Analysis of Sedentary Behaviour in Mass Media Campaigns” by Knox E et al. Journal of Physical Activity \& Health

(C) 2014 Human Kinetics, Inc.

engagement with $\mathrm{MVPA}^{40}$. Unimaginative messages which dwell on underdeveloped sedentary behaviour guidelines are unlikely to provide the motivation to improve behaviour as they may be similarly unable to provide optimally-challenging attainable goals and lack specific information. Latimer-Cheung and colleagues recently called for a strategy to disseminate physical activity guidelines ${ }^{41}$. The emergence of the sedentary behaviour topic within physical activity campaigns suggests that a strategy to develop messages targeting sedentary behaviour is also required.

The promotion of sedentary behaviour offers a gateway to more active lifestyles but current messages are not capitalising on the full activity spectrum. Theme two shows a persistent focus on swapping sedentary behaviour for physical activities instead of less intense activities such as standing. Consequently, a lack of awareness regarding the independent benefits of limiting sitting time could make it more difficult to convince the general population that swapping sedentary behaviours for activity that is only marginally more active (i.e. sitting for standing) and does not constitute MVPA, holds value 9,33,42 $^{\text {. }}$ Anecdotal evidence from internet discussions and public responses to news items regarding sedentary behaviour suggests that portions of the general public are aware that too much sitting is bad for their health but do not recognise that modifications as small as standing during the commercial break of a television programme can improve health (e.g. "It's not that these scientific edicts aren't correct it's the whole 'state the bleeding obviousness' of it I can live without"; "There's nothing that we can do other than installing treadmills behind every school and office desk" [comments posted in response to the BBC News article "Sitting for long periods is 'bad for your health"'17). Further, individuals are sedentary for around six hours a day ${ }^{7}$. Intuitively, it seems unlikely that individuals will be persuaded to change all of this behaviour into physical activity such as running, bicycling etc. Such ambitious messages could be motivationally deleterious for the majority of adults who are currently engaging in 
“Accounting for Sitting and Moving: An Analysis of Sedentary Behaviour in Mass Media Campaigns” by Knox E et al. Journal of Physical Activity \& Health

(C) 2014 Human Kinetics, Inc.

almost no physical activity ${ }^{43,44}$. Messaging campaigns targeting large (or entire) populations may benefit from being realistic rather than idealistic. As discussed by Hamilton and colleagues the proportion of the day taken up with 'nonexercise' activity (NEAT) far exceeds that taken up by exercise (i.e. MVPA) ${ }^{45}$. By neglecting low intensity behaviours such as standing, a large 'window of opportunity' is being lost in terms of accumulating health benefits over the course of an entire day. Offering greater flexibility in the time of day at which lifestyle changes can occur and encouraging smaller steps towards an active lifestyle may be more realistic and therefore effective in motivating positive behavioural change ${ }^{46,39}$. Positively-framed messages around sedentary behaviour offer more achievable small steps towards generally more active lifestyles. Reducing sedentary behaviour may be seen as a first step on the physical activity continuum and presents a more attainable option for most individuals ${ }^{47}$. Messages which encourage reduced sedentary behaviour may resultantly have the potential for greater population health gains than messages which only promote MVPA due to a greater likelihood of compliance ${ }^{48}$.

The failure of campaigns to promote light intensity activity and instead tie sedentary behaviour messages to those on MVPA leads us to another theme. The third identified theme is the possibility that messages regarding sedentary behaviour could confuse perceptions around MVPA and even detract from its perceived importance. Reducing sedentary behaviour requires increased engagement with active alternatives but it does not necessarily follow that these alternatives will result in the accumulation of more MVPA. Some research suggests it is more likely that sedentary time will be replaced with light forms of physical activity rather than guideline-fulfilling $\mathrm{MVPA}^{49}$. Many advertisements recommend substituting sedentary behaviours with activities such as taking the stairs instead of the lift and walking from the car to the supermarket, and suggest such adjustments will contribute towards individuals meeting MVPA guidelines. However, these activities were never 
“Accounting for Sitting and Moving: An Analysis of Sedentary Behaviour in Mass Media Campaigns” by Knox E et al. Journal of Physical Activity \& Health

(C) 2014 Human Kinetics, Inc.

intended to be promoted as guideline-fulfilling MVPA but to be reinforced as part of the regular 'active lifestyle' routine ${ }^{33}$. These messages could contribute to misperceptions regarding MVPA engagement in adults and lead to a devaluation of engaging in true MVPA $^{50,51,52,53,54,55,56}$. While reducing sedentary behaviour in itself can result in some health gains $^{19}$, it is important that this is not seen as an alternative to increasing MVPA. Indeed, engaging in more intense forms of physical activity is still likely to provide the greatest health returns ${ }^{57}$, notwithstanding the difficulty (perceived and/or actual) of achieving such levels. In addition, the 150 minute a week MVPA guideline is based on the assumption that people already engage in regular lifestyle activity. Those who engage in little lifestyle activity may need to do more MVPA for good health, while those with very active daily lives can probably do less. Health promotion experts need to account for an increasingly heterogeneous range of behaviours outside of an 'active-sedentary' dichotomy. It is important that the current media interest in sedentary behaviour does not result in messages regarding MVPA being lost.

The fourth identified theme is the demonization of sedentary behaviour. A recent campaign launched in the UK entitled Movelhour carries a logo which depicts a chair with a skull as the back-rest, alongside the slogan "Sitting is the new enemy". (https://www.facebook.com/MOVE1HOUR). The messages examined in the present study were similarly negative with regards to sedentary behaviours, although perhaps less extreme. Such aggressive messaging approaches seem unwise in light of the lack of evidence to support their efficacy, especially considering findings that fear appeals and negative framing may not be motivational ${ }^{58,59,60}$. Some sedentary behaviour is essential and even valuable. Cars enable individuals to travel longer distances, family meal times are spent sat at the table and for many computers are a necessary part of the working day. The Change4Life poster "Risk an early death, just do nothing", inflamed some individuals and societal groups to the extent 
“Accounting for Sitting and Moving: An Analysis of Sedentary Behaviour in Mass Media Campaigns” by Knox E et al. Journal of Physical Activity \& Health

(C) 2014 Human Kinetics, Inc.

that an alternative poster was independently printed carrying the same message but alongside a picture of a child sat reading. Clearly, a more thorough consideration of the contribution of sedentary behaviour and its place in society is needed before messages castigating it are disseminated.

\section{Future directions}

We suggest three areas to focus future research. First, it is important to investigate whether messages on sedentary behaviour and physical activity can and should be presented together. Researchers need to consider the repercussions of presenting the two types of messages together on comprehension and motivation, and reflect on this when pilot-testing campaigns. This requires an investigation into the effects of one type of message on the other and vice versa. So far, research has only focused on the effect of physical activity messages on the understanding of physical activity behaviours ${ }^{61,62,59,60,63,64,65,66,58,67,68,69,70,71,72,73,74,75,76,77}$. However, we posit that physical activity messages will influence understanding of sedentary behaviours and, in the same way, messages regarding sedentary behaviour will influence perceptions of physical activity. Research into the implications of this symbiotic relationship is needed to align these two important areas of research through messages which compliment rather than contradict. In addition, the contexts and populations in which each type of message is presented will be influential. For instance, messages regarding sedentary behaviour are likely to have a very different influence on perceptions when presented in a workplace or school environment relative to a gym or a leisure centre.

Second, different strategies of combining messages should be explored. Health campaigns could emphasise the reduction of sedentary behaviour, as exemplified by the 5210 campaign which targets "two hours or less recreational screen time", or the introduction of more light activity as seen in the tips section of the Change4Life website; "The furthest 
“Accounting for Sitting and Moving: An Analysis of Sedentary Behaviour in Mass Media Campaigns” by Knox E et al. Journal of Physical Activity \& Health

(C) 2014 Human Kinetics, Inc.

parking space could be good for you". These subtle differences may influence the way in which campaigns are perceived. Messages around changing lifestyle to improve both health behaviours should be a focus of future research. Brawley and Latimer have previously discussed the need for messages on MVPA guidelines to inform individuals how more MVPA may be engaged ${ }^{78}$. We agree with these sentiments and suggest that such information should also be present in sedentary behaviour guidelines from the outset. Viable strategies for replacing sedentary behaviour with both light activity and MVPA should be investigated.

Finally, if theories typically used to understand physical activity behaviour such as the $\mathrm{TPB}^{79}$ are also to be applied to understanding sedentary behaviour, work is required to see how appropriate they are and whether modifications are needed or new approaches should be $\operatorname{adopted}^{80}$.

\section{Conclusion}

Wareham and Brage have called for caution when delivering public health messages and suggested changes should only be made when the evidence is robust ${ }^{81}$. Excessive sedentary time presents a major health threat ${ }^{82,83}$ causing some health campaigns to introduce sedentary messages despite lacking evidence to inform them. This analysis of major activityrelated campaigns in four countries identified four themes associated with messaging sedentary behaviour: clinging to guidelines, sedentary behaviour as a first step on the physical activity continuum, complicating the promotion of MVPA and the demonization of sedentary behaviour. A consortium of academics, policy-makers and marketing experts from the realms of physical activity and sedentary behaviour should be brought together to synthesise existing research and stimulate new research to inform further development of guidelines, more expansive shaping of health campaigns and successful execution of activityrelated messages. 
“Accounting for Sitting and Moving: An Analysis of Sedentary Behaviour in Mass Media Campaigns” by Knox E et al. Journal of Physical Activity \& Health

(C) 2014 Human Kinetics, Inc.

\section{References}

1. Wilmot EG, Edwardson CL, Achana FA, et al. Sedentary time in adults and the association with diabetes, cardiovascular disease and death: Systematic review and meta-analysis. Diabetologia. 2012;55:2895-2905.

2. Townsend N, Bhatnager P, Wickramasinghe K, Scarborough P, Foster C, Rayner M. Physical Activity Statistics 2012. London; 2012:1-131.

3. Carson V, Janssen I. Volume, patterns, and types of sedentary behavior and cardiometabolic health in children and adolescents: A cross-sectional study. BMC Public Health. 2011;11(1):274.

4. Yates T, Wilmot EG, Davies MJ, et al. Sedentary behavior: What's in a definition? Am J Prev Med. 2011;40(6):e33-e34.

5. Proper KI, Singh AS, van Mechelen W, Chinapaw MJ. Sedentary behavior: What's in a definition? Am J Prev Med. 2011;40(6):e34.

6. Sedentary Behaviour Research Network. Letter to the Editor: Standardized use of the terms "sedentary" and "sedentary behaviours." Appl Physiol Nutr Metab.

2012;542(February):540-542.

7. Bauman A, Ainsworth BE, Sallis JF, et al. The descriptive epidemiology of sitting. A 20-country comparison using the International Physical Activity Questionnaire (IPAQ). Am J Prev Med. 2011;41(2):228-235.

8. Department of Health Physical Activity Health Improvement and Protection. Start Active, Stay Active: A Report on Physical Activity for Health from the Four Home Countries' Chief Medical Officers. London: Department of Health; 2011.

9. Staiano AE, Harrington DM, Barreira TV, Katzmarzyk PT. Sitting time and cardiometabolic risk in US adults: Associations by sex, race, socioeconomic status and activity level. Br J Sports Med. 2014;48(3):213-219.

10. Nash H. Navigating Choppy Waters: CBI/Harvey Nash Employment Trends Survey 2011. London, UK: CBI; 2011:1-44.

11. Leveson Gower T, Analysis and Disemmination. 2011 Census Analysis - Method of Travel to Work in England and Wales Report. (Office for National Statistics, ed.). London: Crown; 2013:1-28.

12. Ofcom. Children and Parents: Media Use and Attitudes Report.; 2012:1-205.

13. Department for Transport. National Travel Survey 2010.; 2011:1-9.

14. George ES, Rosenkranz RR, Kolt GS. Chronic disease and sitting time in middle-aged Australian males: Findings from the 45 and Up Study. Int J Behav Nutr Phys Act. 2013;10(1):20-27.

15. Patel AV, Bernstein L, Deka A, et al. Leisure time spent sitting in relation to total mortality in a prospective cohort of US adults. Am J Epidemiol. 2010;172(4):419-429. 
"Accounting for Sitting and Moving: An Analysis of Sedentary Behaviour in Mass Media Campaigns" by Knox E et al. Journal of Physical Activity \& Health

(C) 2014 Human Kinetics, Inc.

16. Wakefield MA, Loken B, Hornik RC. Use of mass media campaigns to change health behaviour. Lancet. 2010;376(9748):1261-1271.

17. Sitting for long periods "is bad for your health." BBC News Heal. 2012. Available at: http://www.bbc.co.uk/news/health-19910888. Accessed October 10, 2013.

18. Exercise: How to keep fit at your desk. Huffingt Post UK. 2013. Available at: http://www.huffingtonpost.co.uk/2013/09/12/how-to-keep-fit-at-yourdesk_n_3912496.html.

19. Hamilton MT, Healy GN, Dunstan DW, Theodore W, Owen N. Too little exercise and too much sitting: Inactivity physiology and the need for new recommendations on sedentary behavior. Curr Cardiovasc Risk Rep. 2008;2(4):292-298.

20. Healy GN, Eakin EG, LaMontagne AD, et al. Reducing sitting time in office workers: Short-term efficacy of a multicomponent intervention. Prev Med. 2013;57(1):43-48.

21. Carr LJ, Karvinen K, Peavler M, Smith R, Cangelosi K. Multicomponent intervention to reduce daily sedentary time: A randomised controlled trial. BMJ Open. 2013;3(10):1-10.

22. Parry S, Straker L, Gilson ND, Smith AJ. Participatory workplace interventions can reduce sedentary time for office workers - a randomised controlled trial. PLoS One. 2013;8(11):1-10.

23. Lobstein T (IASO), ed. A Report of the UP4FUN Project to Reduce Sedentary Behaviour among Children, with Recommendations for Implementing Similar Projects across Europe. Amsterdam: ENERGY-project Consortium; 2012:1-59.

24. Townsend RC, Bennis W. Up the Organization: How to Stop the Corporation from Stifling People and Strangling Profits. San Francisco, CA: Wiley; 2007:1-208.

25. Hsieh HF, Shannon SE. Three approaches to qualitative content analysis. Qual Health Res. 2005;15(9):1277-1288.

26. National Coalition for Promoting Physical Activity. National Physical Activity Plan for the United States. 2010.

27. Tremblay MS, Warburton DER, Janssen I, et al. New Canadian physical activity guidelines. Appl Physiol Nutr Metab. 2011;36(1):36-58.

28. Australian Government Department of Health. Make Your Move - Sit Less Be Active for Life! 2014.

29. 5210 Let's Go! Maine. 2012. Available at: http://www.letsgo.org/. Accessed October $28,2013$.

30. Department of Health. Change4Life Local Supporter's Guide.; 2010.

31. Change4Life. Up \& about: Why Kids Shouldn't Veg out and How to Get Them up and about.; 2010.

32. Carson V, Ridgers ND, Howard BJ, et al. Light-intensity physical activity and cardiometabolic biomarkers in US adolescents. PLoS One. 2013;8(8):1-7. 
“Accounting for Sitting and Moving: An Analysis of Sedentary Behaviour in Mass Media Campaigns” by Knox E et al. Journal of Physical Activity \& Health

(C) 2014 Human Kinetics, Inc.

33. Dunstan DW, Kingwell B, Larsen R, et al. Breaking up prolonged sitting reduces postprandial glucose and insulin responses. Diabetes Care. 2012;35:976-983.

34. Australian Government. Swap It Don’t Stop It. 2011.

35. Mansoubi M, Pearson N, Clemes S, Biddle SJH. The relationship between sedentary behaviour and physical activity in adults: A systematic review. Prev Med. 2014.

36. National Health Services. Food and diet. NHS Choices. Available at: http://www.nhs.uk/livewell/goodfood/Pages/Goodfoodhome.aspx.

37. Drinkaware. Daily Unit Guidelines. 2013. Available at: https://www.drinkaware.co.uk/check-the-facts/what-is-alcohol/daily-guidelines.

38. Canadian Society for Exercise Physiology. Canadian Sedentary Behaviour Guidelines.; 2013:3-5.

39. Manns PJ, Dunstan DW, Owen N, Healy GN. Addressing the nonexercise part of the activity continuum: A more realistic and achievable approach to activity programming for adults with mobility disability? Phys Ther. 2012;92(4):614-625.

40. Knox ECL, Webb OJ, Esliger DW, Biddle SJH, Sherar LB. Using threshold messages to promote physical activity: Implications for public perceptions of health effects. Eur J Public Health. 2014;24(2):195-199.

41. Latimer-Cheung AE, Rhodes RE, Kho ME, et al. Evidence-informed recommendations for constructing and disseminating messages supplementing the new Canadian Physical Activity Guidelines. BMC Public Heal. 2013;13:419-431.

42. Dunstan DW, Thorp AA, Healy GN. Prolonged sitting: Is it a distinct coronary heart disease risk factor? Curr Opin Cardiol. 2011;26(5):412-419.

43. Chaudhury M, Esliger D. Accelerometry in adults. In: Craig R, Mindell J, Hirani V, eds. Health Survey for England 2008: Volume 1 Physical Activity and Fitness.Vol 1. Leeds: The Health and Social Care Information Centre; 2009.

44. Trost SG, Owen N, Bauman A, Sallis JF, Brown W. Correlates of adults' participation in physical activity: Review and update. Med Sci Sports Exerc. 2002;34(12):19962001.

45. Hamilton MT, Hamilton DG, Zderic TW. Role of low energy expenditure and sitting in obesity, metabolic syndrome, type 2 diabetes, and cardiovascular disease. Perspect Diabetes. 2007;56:2655-2667.

46. Bar-Eli M, Tenenbaum G, Pie JS, Btesh Y, Almog A. Effect of goal difficulty, goal specificity and duration of practice time intervals on muscular endurance performance. J Sports Sci. 1997;15:125-135.

47. Owen N, Healy GN, Matthews C, Dunstan DW. Too much sitting: The populationhealth science of sedentary behavior. Exerc Sport Sci Rev. 2010;38(3):105-113.

48. Katzmarzyk PT, Mason C. The physical activity transition. J Phys Act Heal. 2009;6(1):269-280. 
“Accounting for Sitting and Moving: An Analysis of Sedentary Behaviour in Mass Media Campaigns” by Knox E et al. Journal of Physical Activity \& Health

(C) 2014 Human Kinetics, Inc.

49. Healy GN, Dunstan DW, Salmon J, et al. Objectively measured light-intensity associated with 2-h plasma glucose. Diabetes Care. 2007;30:1384-1389.

50. Watkinson C, van Sluijs EMF, Sutton S, Hardeman W, Corder K, Griffin SJ. Overestimation of physical activity level is associated with lower BMI: A crosssectional analysis. Int J Behav Nutr Phys. 2010;7(1):68-76.

51. Lechner L, Bolman C, Van Dijke M. Factors related to misperception of physical activity in the Netherlands and implications for health promotion programmes. Health Promot Int. 2006;21(2):104-112.

52. Van Sluijs EMF, Griffin SJ, van Poppel MNM. A cross-sectional study of awareness of physical activity: Associations with personal, behavioral and psychosocial factors. Int J Behav Nutr Phys Act. 2007;4(1):53-61.

53. Bolman C, Lechner L, Dijke M Van. Question order in the assessment of misperception of physical activity. Int J Behav Nutr Phys Act. 2007;4:42-52.

54. Ronda G, Van Assema P, Brug J. Stages of change, psychological factors and awareness of physical activity levels in The Netherlands. Health Promot Int. 2001;16(4):305-314.

55. Van Stralen MM, de Vries H, Mudde AN, Bolman C, Lechner L. The long-term efficacy of two computer-tailored physical activity interventions for older adults: Main effects and mediators. Heal Psychol. 2011;30(4):442-452.

56. Vandelanotte C, Mummery WK. Qualitative and quantitative research into the development and feasibility of a video-tailored physical activity intervention. Int $J$ Behav Nutr Phys Act. 2011;8:70-80.

57. Warburton DER, Nicol CW, Bredin SSD. Health benefits of physical activity: The evidence. Can Med Assoc J. 2006;174(6):801-809.

58. Cho H, Salmon CT. Fear appeals for individuals in different stages of change: Intended and unintended effects and implications on public health campaigns. Health Commun. 2006;20(1):91-99.

59. Gallagher KM, Updegraff JA. Health message framing effects on attitudes, intentions, and behavior: A meta-analytic review. Ann Behav Med. 2012;43(1):101-116.

60. Latimer AE, Brawley LR, Bassett RL. A systematic review of three approaches for constructing physical activity messages: What messages work and what improvements are needed? Int J Behav Nutr Phys Act. 2010;7:36-52.

61. Noar SM, Benac CN, Harris MS. Does tailoring matter? Meta-analytic review of tailored print health behavior change interventions. Psychol Bull. 2007;133(4):673693.

62. Gallagher KM, Updegraff JA. When "fit" leads to fit, and when "fit" leads to fat: How message framing and intrinsic vs. extrinsic exercise outcomes interact in promoting physical activity. Psychol Heal. 2011;26(7):819-834. 
“Accounting for Sitting and Moving: An Analysis of Sedentary Behaviour in Mass Media Campaigns” by Knox E et al. Journal of Physical Activity \& Health

(C) 2014 Human Kinetics, Inc.

63. Gray JB, Harrington NG. Narrative and framing: A test of an integrated message strategy in the exercise context. J Health Commun. 2011;16(3):264-281.

64. Latimer AE, Salovey P, Rothman AJ. The effectiveness of gain-framed messages for encouraging disease prevention behavior: Is all hope lost? J Health Commun. 2007;12(7):645-649.

65. Why YP, Huang RZ, Sandhu PK. Affective messages increase leisure walking only among conscientious individuals. Pers Individ Dif. 2010;48(6):752-756.

66. Brengman M, Wauters B, Macharis C, Mairesse O. Functional effectiveness of threat appeals in exercise promotion messages. Psicologica. 2010;31:577-604.

67. Webb OJ, Eves FF. Promoting stair climbing: Effects of message specificity and validation. Health Educ Res. 2007;22(1):49-57.

68. Parrott MW, Tennant LK, Olejnik S, Poudevigne MS. Theory of planned behavior: Implications for an email-based physical activity intervention. Psychol Sport Exerc. 2008;9(4):511-526.

69. Jones LW, Sinclair RC, Courneya KS. The effects of source credibility and message framing on exercise intentions, behaviors, and attitudes: An integration of the elaboration likelihood model and prospect theory. J Appl Soc Psychol. 2003;33(1):179-196.

70. Bull FC, Kreuter MW, Scharff DP. Effects of tailored, personalized and general health messages on physical activity. Patient Educ Couns. 1999;36(2):181-92.

71. Hageman PA, Walker SN, Pullen CH. Tailored versus standard internet-delivered interventions to promote physical activity in older women. J Geriatr Phys Ther. 2005;28(1):28-33.

72. Langille JLD, Berry TR, Reade IL, Witcher C, Loitz CC, Rodgers WM. Strength of messaging in changing attitudes in a workplace wellness program. Health Promot Pract. 2011;12(2):303-311.

73. Quintiliani LM, Campbell MK, Bowling JM, Steck S, Haines PS, DeVellis BM. Results of a randomized trial testing messages tailored to participant-selected topics among female college students: Physical activity outcomes. J Phys Act Heal. 2010;7(4):517-526.

74. Priebe CS, Spink KS. Using messages promoting descriptive norms to increase physical activity. Health Commun. 2012;27(3):284-91.

75. Park HS, Smith SW. Distinctiveness and Influence of Subjective Norms, Personal Descriptive and Injunctive Norms, and Societal Descriptive and Injunctive Norms on Behavioral Intent: A Case of Two Behaviors Critical to Organ Donation. Hum Commun Res. 2007;33(2):194-218.

76. Gaston A, Gammage KL. The effectiveness of a health-based message on pregnant women's intentions to exercise postpartum. J Reprod Infant Psychol. 2011;29(2):162169. 
“Accounting for Sitting and Moving: An Analysis of Sedentary Behaviour in Mass Media Campaigns" by Knox E et al. Journal of Physical Activity \& Health

(C) 2014 Human Kinetics, Inc.

77. Gaston A, Gammage KL. Health versus appearance messages, self-monitoring and pregnant women's intentions to exercise postpartum. J Reprod Infant Psychol. 2010;28(4):345-358.

78. Brawley LR, Latimer AE. Physical activity guides for Canadians: Messaging strategies, realistic expectations for change, and evaluation. Appl Physiol Nutr Metab. 2007;32(S2E):S170-S184.

79. Ajzen I. The theory of planned behavior. Organ Behav Hum Decis Process. 1991;50:179-211.

80. Biddle S. Fit or sit? Is there a psychology of sedentary behaviour? Sport Exerc Psychol Rev. 2011;7(2):5-10.

81. Wareham NJ, Brage S. Commentary: Physical activity and obesity; scientific uncertainty and the art of public health messaging. Int J Epidemiol. 2013;42(6):18431845.

82. Ekelund U. Commentary: Too much sitting - a public health threat? Int J Epidemiol. 2012;41(5):1353-1355.

83. Dunstan DW, Howard B, Healy GN, Owen N. Too much sitting - a health hazard. Diabetes Res Clin Pract. 2012;97(3):368-376. 
“Accounting for Sitting and Moving: An Analysis of Sedentary Behaviour in Mass Media Campaigns" by Knox E et al.

Journal of Physical Activity \& Health

(c) 2014 Human Kinetics, Inc.

Table 1. Examples of messages from major campaigns in the UK, US, Canada and Australia promoting physical activity and reduced sedentary behaviour

\begin{tabular}{|c|c|c|c|c|c|}
\hline Campaign & $\begin{array}{l}\text { Example of a physical } \\
\text { activity message for } \\
\text { children }\end{array}$ & $\begin{array}{l}\text { Example of a physical } \\
\text { activity message for } \\
\text { adults }\end{array}$ & $\begin{array}{l}\text { Example of a sedentary } \\
\text { message for children }\end{array}$ & $\begin{array}{l}\text { Example of a sedentary } \\
\text { message for adults }\end{array}$ & $\begin{array}{l}\text { Empirical investigation of } \\
\text { reach or effectiveness }\end{array}$ \\
\hline Change4Life & $\begin{array}{l}60 \text { active minutes ( } 2009 \\
\text { Poster) }\end{array}$ & $\begin{array}{l}\text { Walking is one free, fun } \\
\text { and flexible way for } \\
\text { adults to get going and } \\
\text { build towards their } \\
\text { weekly } 150 \text { active } \\
\text { minutes ( } 2011 \\
\text { Newsletter) }\end{array}$ & $\begin{array}{l}\text { Setting a limit of two } \\
\text { hours max of screen } \\
\text { time each day helps } \\
\text { make sure kids are } \\
\text { active" }\end{array}$ & $\begin{array}{l}\text { Swap four wheels for } \\
\text { my own two feet }\end{array}$ & $\begin{array}{l}\text { Large reach and high } \\
\text { awareness in the population } \\
\text { have been reported }{ }^{1,2} \text {. } \\
\text { Inconsistencies in the } \\
\text { campaign messages have } \\
\text { also been highlighted }{ }^{3} \text {. }\end{array}$ \\
\hline $5-2-1-0$ & $\begin{array}{l}1 \text { hour or more of } \\
\text { physical activity } \\
\text { (http://www.letsgo.org/) }\end{array}$ & $\mathrm{X}$ & $\begin{array}{l}2 \text { hours or less } \\
\text { recreational screen time } \\
\text { (http://www.letsgo.org/) }\end{array}$ & $\mathrm{X}$ & $\begin{array}{l}\text { Little empirical research. } \\
\text { First year evaluation } \\
\text { suggests reaching over } \\
320,000 \text { kids }^{4} \text {. }\end{array}$ \\
\hline $\begin{array}{l}\text { ParticipACTIO } \\
\text { N }\end{array}$ & $\begin{array}{l}\text {...revive hide and seek, } \\
\text { let's give them } 60 \\
\text { minutes a day of } \\
\text { physical activity ( } 2012 \\
\text { Bring Back Play } \\
\text { television advert) }\end{array}$ & $\begin{array}{l}\text { Get inspired. Get } \\
\text { moving }\end{array}$ & Unplug and play & Park the car & $\begin{array}{l}\text { Reports of large reach and } \\
\text { high awareness of } \\
\text { messages }{ }^{5} \text {. Credited as being } \\
\text { the most successful } \\
\text { campaign ever }{ }^{6} .\end{array}$ \\
\hline $\begin{array}{l}\text { Australian HF } \\
\text { Campaigns }\end{array}$ & $\mathrm{X}$ & $\begin{array}{l}\text { Walk yourself happy. } \\
\text { Just } 30 \text { mins a day be } \\
\text { active. }\end{array}$ & $\mathrm{X}$ & Swap sitting for moving & $\begin{array}{l}\text { Little evaluation. Only } \\
\text { aspects of the sub-campaign } \\
\text { Measure Up has been } \\
\text { evaluated. Awareness was } \\
\text { high but was lowest amongst } \\
\text { inactive adults }{ }^{7} \text {. }\end{array}$ \\
\hline
\end{tabular}

1. Department of Health (2010). Change4Life One Year On. 2. Croker et al (2012). BMC:Public Health. 3. Piggin (2012). Health Policy. 4. Let's Go (2013) Annual Report. 5. ParticipACTION (2004) Canadian Journal of Public Health Special Supplement. 6. Faulkner et al. (2011) Health Promotion Practice. 7. Department of Health and Aging (2010). Evaluation of the Measure Up Campaign. 